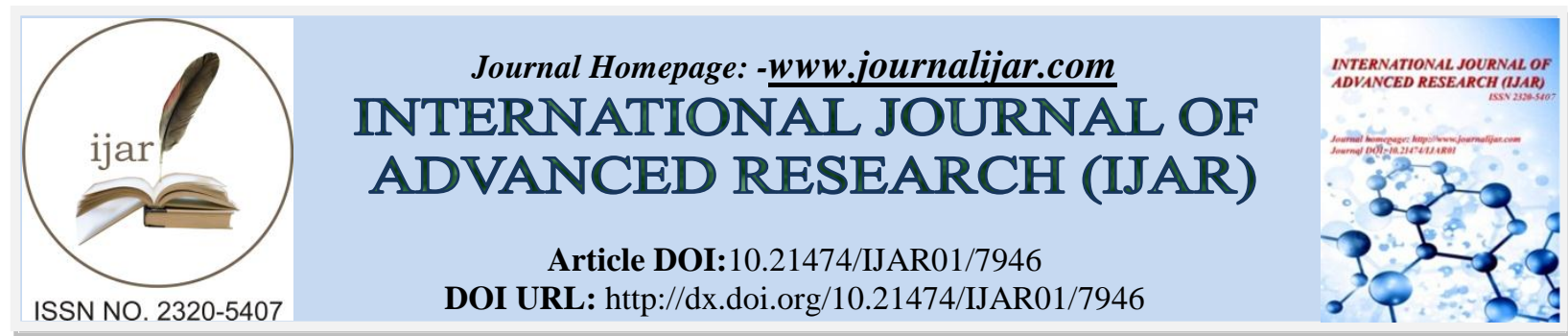

RESEARCH ARTICLE

\title{
THE INFLUENCE OF ORGANIZATIONAL CULTURE ON INTELLIGENT SYSTEMS ADOPTION IN HIGHER LEARNING ACADEMIES.
}

Douglas Omwenga Nyabuga ${ }^{1}$, Emmanuel OchakoManyange ${ }^{2}$ and Erick IsabokeNyasani ${ }^{3}$. Mount Kenya University - Kigali (Rwanda).

\section{Manuscript Info}

\section{Manuscript History}

Received: 16 August 2018

Final Accepted: 18 September 2018

Published: October 2018

Keywords:-

Organization; Culture; Information

Systems; Adoption

\begin{abstract}
Implementation of intelligent systems in institutions of higher learning has been a big challenge due to organizational issues e.g., the users' resistance to new technologies. The aim of this study was to investigate how organizational culture has influenced the adoption and usage of the information systems in teaching. The general objective was then narrowed down to three specific objectives namely to establish whether the organizational culture influences the acceptance, embracing, and usage of intelligent systems among the instructors of higher learning institutions, and examine the instructors' practices in regard to the use of intelligent systems in service. The study adopted descriptive research design with the target population of 150 members of academic staff and the sample size of 109 that was determined by Sloven's formula. Simple random selection method was used in order to choose a representative section without being prejudiced.The researcher used the questionnaire as data collection instrument and finally the data was analyzed using the statistical package for social science (SPSS). The major findings of this study indicate that organizational culture has influenced the adoption and usage of the intelligent systems in teaching in various institutions of learning. It also revealed that the institution beliefs, customs, values, conduct has a positive influence on the embracing of intelligent systems in service delivery. Most of the results fell within the required standard $\mathrm{p}$-value of $<0.05$.
\end{abstract}

Copy Right, IJAR, 2018,. All rights reserved.

\section{Introduction:-}

A society is astructured system which comprises of strong ideas or vision, shared goals which motivates and directs a group of individuals working interdependently [1]. The organizational culture deals with how the individuals conduct and behaviors within such an organization under the same set of rules, values, beliefs, customs, habits, language, systems, and principles which define who they are as well as the managerial styles [2].

The intelligent systems include the computer networking, people, data, computer hardware and software that people in the organization or the institution adopt for gathering, cleaning, and handling of the data or information as well the circulation [3]. The authorization of intelligent systems e.g., telecommunication, the application software such as databases, the data warehousing, the computer systems, the human resources, and the quality standards involve an immense and complex process. This process of authorization determines inner or exterior changes of the institution with the embracing and usage of intelligent systems anticipated. 
For the academy to implement the acceptance of intelligent systems productively or unproductively is exclusively influenced by the organizational culture, its values, practices, procedures or processes and guidelines, goals, and objectives, vision. An institution that is ready to support the implementation of information systems in teaching and rendered services makes it easy for the employees to adopt it without resistance [4]. Disappointment on the adoption of the intelligent systems in academies is linked to organizational cultural ecofriendly [5].

A benevolent practice encourages the individuals mostly the instructors in academies to be open-minded in learning of new technologies through attempting and trying new metrics of instructing, innovative, and advanced skills. The entire achievement is accomplished by the influence of society practices and beliefs. On the contrary, the society practices that does not support and encourage the embracing of intelligent systems thus contributes to negligence and resistance to part or whole new technologies for its use in service delivery [6].

Full realization and exploration of the intelligent systems by instructors has not been achieved in several institutions [7], [8] hence, making it very difficult for the education sector to incorporate the use of intelligent systems in teaching. Previous research shows that the structural and cultural factors represent a significant part in the acceptance of intelligent systems in the organizations [9], whereby organizational culture determines the facilitation or hindrance of the process of adoption of the intelligent systems [10], [11]. Therefore, institution of higher learning need to identify these organizational culture features and their influence in the use of IS because not all organizations understands the benefits and usefulness of intelligent systems.

The process of adopting, incorporating intelligent systems in the teaching in institutions is so challenging due to different levels that exists. Recent research findings indicate that the main contributor of the minimum response is traditional organizational cultures that are still upheld [12]. Therefore, this research will establish whether the organizational culture influences the acceptance, embracing, and usage of intelligent systems among the instructors of academies, and examine the instructors' practices in regard to the use of intelligent systems in service delivery. Figure 1 below is an illustration of the OC and IS factors that are mostly likely to add to the embracing of intelligent systems among the instructors in academies.

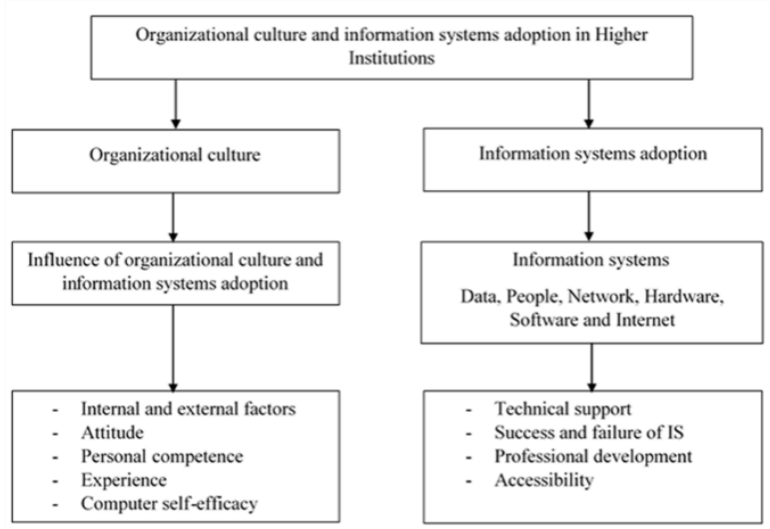

Fig. 1:-Organization Culture and Intelligent Systems Adoption

The rest of the work is arranged as depicted: part II the interrelated work, part III the study techniques, part IV the data investigation and results, and part $\mathrm{V}$ the conclusions, suggestions, and acknowledgement.

\section{Related Work:-}

Different society and institutional practices have been incorporated in the study on the theory of society practices and their impact on intelligent systems usage e.g., the theory of anthropology perceives society practices as an allegory for the institutions and the theory of sociology or folklore that describes the functionalists that the organizational enjoys. Majority of the implementations of the institution cultures on the simple customs, formulated, learnt and discovered by a group of persons is due to their learning how on to adapt, handle and incorporate the challenges they do face internally or externally [13], as illustrated in Fig. 3 below; 


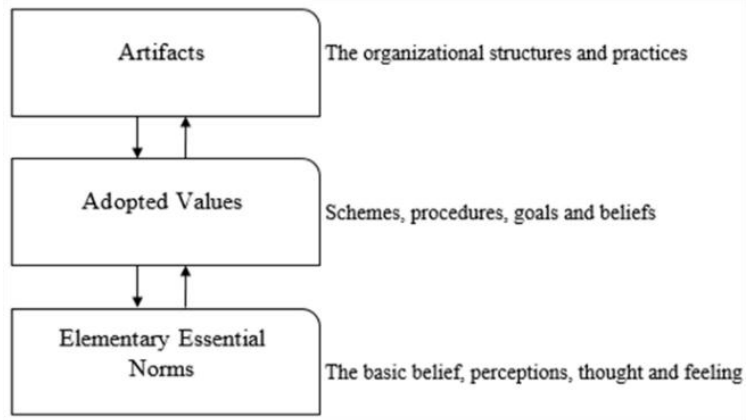

Fig. 2:-The diagrammatic representation of Organizational Culture theories

\section{Information systems and institutional culture:-}

The agreed regulations, what people believe in, their knowledge, the shared customs among these persons or individuals thus describes the organizational culture [14]. Their behaviors, expressions, the functions of the organization, their efficiency in duties, the power and authority of managers, the systems of governance in hierarchical way, the designing and implementation of the laid down policies and standards, and the administration of the intelligent systems processes is thus, subjective to the society practices and norms [15]. This clearly indicates that the influence of organization culture is so great on the instructors' feelings allied to work e.g., duty contentment, loyal to the institute due to its values, beliefs, assumptions, capability, and their readiness to use these technologies for performance improvement [16], [14].

Impelling elements for intelligent systems (IS) adoption: two types of elements namely; inner and exterior influence the adoption of IS through which the inner factors are executed and handled internally by organization administration and thus, the exterior factors are managed externally.

Inner elements: in situations where the institutions are open to novel threats and tests, the embracing and implementation of advanced technologies forms an environment and a stage where fresh innovations are embraced that helps these institutions to gain advantage of opponents and rivals. Organizations that are closed up to any new innovations, resistance to revolution do lag behind and thus remain stagnant and ineffective in service [17]. The decision makers play an imperative, significant part in the making, discharge, and utilization of decisions. Decisions such as the adoption and usage of IS in ensuring that it achieves the setup quality standards in order to realize the institutional goals entails the preparation, operation, assessment, sustaining and advancement of the intelligent systems [18], this enable instructors' performance improvement, inclusiveness as well as making correct decision [17].

Exterior elements: successful adoption of intelligent systems in institution of higher learning involve different stakeholders from within or without; the stakeholders can be trading partners or software vendors, service providers of Internet, customers, the competitors, IS specialists [19]. Some circumstance such as fierce threats may force institutions to embrace the use of intelligent systems in order to remain relevant and competitive against their opponents or rivals [20], [21].

The consultative and supporting information of exterior elements have a big influence in the use of IS. The workers' negative perception and resistance against embracing advanced skills, practices, and technologies determine success or failure of it [22], [23]. As the academies share norms, practices, knowledge, and skills, there is a likelihood of these academies sharing complementary and related thoughts on contrary to their codes of conduct which might vary [24].

Institutional values influence and intelligent systems adoption:-

Sensational attitudes and openness of young persons or workforces to learn and adopt the use of IS in institution defines the likelihood of successive integration or resistance of the technologies [25], in comparison to the older instructors who are intensely motivated and controlled by factually and professed social behaviours. To have an effective and efficient implementation of intelligent systems in organization there is need of skills, knowledge sharing, desire to try and experience for all employees regardless of their caliber. 


\section{Information system acceptance:-}

Several factors have to be investigated in the acceptance of the intelligent systems in institutions e.g., the evaluation of the newness of IS to explore the aftermath and its satisfaction, assertion, and realization of the desired probable ratification, and assessing the sustainability of the intended development and creativity [26]. The time the system takes to respond to inputs, the amount of data it can handle and store, up to what level the system can be used, the commitment of instructors or employees to various projects and operations are some of the contributing factors [27].

\section{Intelligent system accomplishment and realization:-}

For academies to realize, and accomplish the embracing of intelligent systems it need devising the right intelligent, proficiency, prowess communications among all individuals of the institutions. Therefore, it is very essential for institutions to lay down strategies for human resource development and frequent trainings to keep them updated with the current technologies and intelligent systems. It has been discovered that the clarity, directness of the intelligent systems and it's easy to use actuates, triggers, and excites the eagerness and preparedness of the instructor to adopt and incorporate IS in tutoring [28].

\section{Intelligent system frustration and decline:-}

According to many research that have been carried out, it has been established that systems fail due to poor designs, user-interface, low interactions, the intelligent systems that are being used do not meet the minimum requirements and expectations of the stakeholders and sometimes due to lack of trainings [28].

\section{Determinants prompting organizational culture towards intelligent systems acceptance:-}

The individual decision either positively or negatively affect the use of intelligent systems in institutions [29]. The intelligent system tools that can be implemented are, for example, the electronic learning resources, networking resources, the Internet resources etc., that enable instructing in institutions [30], [12]. The level of education, the age of an individual, the revenue level, sex, familiarity and the feelings about technology permits greater acceptance, and incorporation of IS into instructing processes.[31]-[34]The higher the familiarity of instructors on the embracing of intelligent systems, the higher the possibility of sure, decisive, and affirmative perspective, belief, mindset and approach and facet for the IS implementation [35].

The ability of the instructors to integrate the use of computers, and some kinds of computer software in instructing predict clearly if the IS will be used or not [36], the instructor' self-efficacy [37], provision and equipping of essential intelligent systems and resources, for example, relevant software makes the achievement, and effectuation of IS effective. Lack of access to these resources hinders the implementation [38]. For successive implementation of the use IS technical support is another important determinant to be considered. In scenarios where there is afall out of technology and there is no help, it automatically leads to user disruptions, and frustrations which lead to resistance [39].

\section{Methodology:-}

The technique used for data collection was a descriptive method in which data was collected through the designing of questionnaires as the main tool for gathering data. These questionnaires carried different kinds of questions that were formulated according to the kind of information the research was looking for and that relevant for the study. These questionnaires were distributed to the respondents who filled them and return the filled questionnaires. In this study a total population of 150 academic staff are distributed but only a sample size of 109 of the respondents was used to determine if the use of intelligent systems in institutions was influenced by organizational culture [40]. 


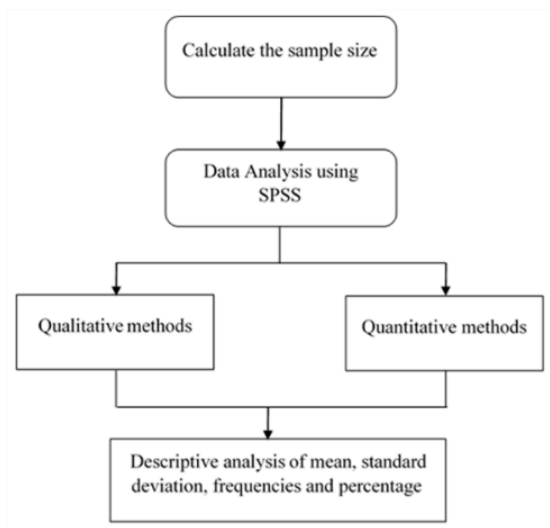

Fig. 3:-Proposed methodology design

\section{Sampled size:-}

The sampled size was calculated out using the following formula:

$$
s=\frac{N}{1+N e^{2}}
$$

Where $s$ stands for the section of the whole population, $N$ the whole community, $e$ is the margin error that is calculated from the confidence level of $95 \%$

Applying Eq. (1), statistical formula shows the calculation of the sample size of our study;

$$
\begin{aligned}
& s=\frac{150}{1+150(0.05)^{2}} \\
& s=\frac{150}{1+150(0.05)^{2}} \\
& s=109
\end{aligned}
$$

Whereby the sample size $(s)=109$

\section{Sample technique:-}

In this research a simple random selection method is used in order to choose a representative section without being prejudiced; this guarantees that each representative of the target community is given equivalent plus selfdetermining chance of inclusiveness in the sample.

\section{Material Investigation:-}

Analysis of the gathered data was processed through statistical package for social science (SPSS) software, the results of the analyzed data is represented in tables. Qualitative and quantitative data analysis methods were used in the study by considering only the influential and important variables that has a p-value of $<0.05$ and which contribute to the main aim of this research. The data investigation was carried out to find out the unique patterns of relationship that exists in the computed data. The descriptive investigation was used to find out the mean, standard deviation, and the frequencies which reveal the attributes with appropriate accuracy in the data collected of a specific group of individuals [40]. This was used to abridge and label the relevant attributes of the population in the organization.

\section{Experiments:-}

The data that was used in carrying out the analysis was collected from the academic staff of a private institution of higher learning i.e., Mount Kenya University- Rwanda; about one hundred and fifty (150) academic staff were given the forms. 


\section{Results \& Discussions:-}

The goal of the study was to establish the influence of organizational culture on intelligent systems adoption in higher learning academies. From the analyzed data the following tables show the relationship that exists between the parameters.

Table 1 below shows the relationship between genders and how they employees respond to internet connectivity. From the two parameters that were tested it clearly shows that there is great correlation due its p-value of 0.029 which is significantly less than the standard $p-$ value $<0.05$.

Table. 1:-Gender vs internet connectivity.

\begin{tabular}{|l|r|r|c|}
\hline & \multicolumn{1}{|c|}{ Value } & df & $\begin{array}{c}\text { Asymp. Sig. } \\
\text { (2-sided) }\end{array}$ \\
\hline Pearson Chi-Square & $10.821^{\text {a }}$ & 4 & .029 \\
\hline Likelihood Ratio & 10.522 & 4 & .032 \\
\hline Linear-by-Linear Association & 4.140 & 1 & .042 \\
\hline N of Valid Cases & 109 & & \\
\hline
\end{tabular}

From table 2 below shows that there is a high frequency significant of 0.007 in regard to the gender and how they respond to the usage of e-mail, internet, word processing, excel, PowerPoint applications in teaching in academies.

Table. 2:-Gender vs intelligent systems applications

\begin{tabular}{|l|r|r|c|}
\hline \multicolumn{2}{|c|}{} & \multicolumn{1}{|c|}{ df } & $\begin{array}{c}\text { Asymp. Sig. (2- } \\
\text { sided) }\end{array}$ \\
\hline Pearson Chi-Square & Value & 3 & .007 \\
\hline Likelihood Ratio & $12.012^{\mathrm{a}}$ & 3 & .006 \\
\hline Linear-by-Linear Association & 12.530 & 3 & .006 \\
\hline N of Valid Cases & 7.567 & 1 & \\
\hline
\end{tabular}

Table 3 below it demonstrations that a greater percentage of the employees are thus satisfied with the IS services that are provided by the organization i.e. a p-value of 0.008 of the tested sample cases of 109 members of instructors.

Table. 3:-The gender against MIS

\begin{tabular}{|l|r|r|c|}
\hline & \multicolumn{1}{|c|}{ Value } & df & Asymp. Sig. (2-sided) \\
\hline Pearson Chi-Square & $13.767^{\text {a }}$ & 4 & .008 \\
\hline Likelihood Ratio & 14.434 & 4 & .006 \\
\hline Linear-by-Linear Association & 3.044 & 1 & .081 \\
\hline N of Valid Cases & 109 & & \\
\hline
\end{tabular}

On age factor of the workers of institutions, table 4 indicates that age contributes to how easy it's for an individual find the information that he/she is looking for on the website. A p-value of 0.011 illustrates that there is great significance in regard to the age of individuals.

Table. 4:-The age against the easiness of the website

\begin{tabular}{|c|c|c|c|}
\hline & Value & $\mathrm{df}$ & Asymp. Sig. (2-sided) \\
\hline Pearson Chi-Square & $21.417^{\mathrm{a}}$ & 9 & .011 \\
\hline Likelihood Ratio & 17.018 & 9 & .048 \\
\hline Linear-by-Linear Association & .773 & 1 & .379 \\
\hline $\mathrm{N}$ of Valid Cases & 109 & & \\
\hline
\end{tabular}

The fact based decisions that are made by the institutions highly influence the adoption of intelligent systems in service delivery, as shown in tables 5 there is a correlation between the parameters; with the p-value of 0.024 and df 
of 40 respectively. This reveals that organizations should make decision basing on facts rather than personal prejudice.

Table. 5:- The fact based decision making

\begin{tabular}{|l|r|c|c|}
\hline & Value & df & $\begin{array}{c}\text { Asymp. Sig. } \\
(2 \text {-sided })\end{array}$ \\
\hline Pearson Chi-Square & $59.511^{\mathrm{a}}$ & 40 & .024 \\
\hline Likelihood Ratio & 54.512 & 40 & .063 \\
\hline Linear-by-Linear Association & 3.640 & 1 & .056 \\
\hline N of Valid Cases & 109 & & \\
\hline
\end{tabular}

From table 6 it clearly shows that the openness of the organization to implement new ideas suggested by the various department has a greater influence on the adoption of IS where the f-significant is 0.000 with a df of 40 .

Table. 6:-The openness of organization to new ideas

\begin{tabular}{|l|r|r|c|}
\hline & \multicolumn{1}{|c|}{ Value } & df & $\begin{array}{c}\text { Asymp. Sig. } \\
\text { (2-sided) }\end{array}$ \\
\hline Pearson Chi-Square & $87.919^{\mathrm{a}}$ & 40 & .000 \\
\hline Likelihood Ratio & 80.278 & 40 & .000 \\
\hline Linear-by-Linear Association & 1.353 & 1 & .245 \\
\hline N of Valid Cases & 109 & & \\
\hline
\end{tabular}

\section{Conclusion:-}

The research demonstrated that the organizational culture has influenced the adoption and usage of the information systems in teaching in various institutions of learning. The analyzed data reveals that the institution beliefs, customs, values, conduct has a positive influence on the embracing of intelligent systems in service delivery. Most of the results fall within the required standard $p-v a l u e<0.05$. This study used questionnaires as a method of data collection and SPSS for data analysis. For future work, we suggest the use of other methods for data collection and analysis.

\section{Acknowledgment:-}

We are so grateful for Mount Kenya University for allowing us to conduct research within their institution. Most thanks goes to all the academic staff for their time, willingness, and readiness to help in filling out the questionnaires.

\section{References:-}

1. J. C. Richmond, V. P., \& McCroskey, An Introduction to Organizational Communication. Los Angeles, CA: Los Angeles, CA: SAGE: Organizational communication, 2009.

2. D. Needle, Business in Context: An Introduction to Business and Its Environment. Thomson, 2004.

3. J. Valacich and C. Schneider, Information Systems Today: Managing the Digital World. NJ, USA: Prentice Hall Press Upper Saddle River, 2009.

4. P. M. Senge, C. R. A. K. P. M. S. Bryan J. Smith, A. Kleiner, C. Roberts, R. B. Ross, and B. J. Smith, The Fifth Discipline Fieldbook: Strategies and Tools for Building a Learning Organization. Currency, Doubleday, 1994.

5. B. P. M. Creemers, "From School Effectiveness and School Improvement to Effective School Improvement: Background, Theoretical Analysis, and Outline of the Empirical Study," Educ. Res. Eval., vol. 8, no. 4, pp. 343-362, Oct. 2002.

6. M. Drent and M. Meelissen, "Which factors obstruct or stimulate teacher educators to use ICT innovatively?," Comput. Educ., vol. 51, no. 1, pp. 187-199, Aug. 2008.

7. E. Shoikova, "Models of technology and change in higher education," in 27th International Spring Seminar on Electronics Technology: Meeting the Challenges of Electronics Technology Progress, 2004., vol. 1, pp. 500-505.

8. M. Jenkins, T. Browne, R. Walker, and R. Hewitt, "The development of technology enhanced learning: findings from a 2008 survey of UK higher education institutions," Interact. Learn. Environ., vol. 19, no. 5, pp. 447-465, Dec. 2011.

9. D. Schneckenberg, "Understanding the real barriers to technology-enhanced innovation in higher education," Educ. Res., vol. 51, no. 4, pp. 411-424, Dec. 2009. 
10. H. Aguinis and H. A. Roth, "Teaching in China: Culture-based Challenges," in Business and Management Education in China, WORLD SCIENTIFIC, 2005, pp. 141-164.

11. P. A. Towndrow, R. E. Silver, and J. Albright, "Setting expectations for educational innovations," J. Educ. Chang., vol. 11, no. 4, pp. 425-455, Nov. 2010.

12. P. Williams, "Lessons from the future: ICT scenarios and the education of teachers," J. Educ. Teach., vol. 31, no. 4, pp. 319-339, Nov. 2005.

13. C. Zhu and N. Engels, "Organizational culture and instructional innovations in higher education," Educ. Manag. Adm. Leadersh., vol. 42, no. 1, pp. 136-158, Jan. 2014.

14. L. J. Bassi, Harnessing the Power of Intellectual Capital, vol. 51. 1997.

15. Á. Cabrera, E. F. Cabrera, and S. Barajas, "The key role of organizational culture in a multi-system view of technology-driven change,” Int. J. Inf. Manage., vol. 21, no. 3, pp. 245-261, Jun. 2001.

16. E. Sikorska-Simmons, "Organizational Culture and Work-Related Attitudes Among Staff in Assisted Living," J. Gerontol. Nurs., vol. 32, no. 2, pp. 19-27, Feb. 2006.

17. T. H. Nguyen, "Information technology adoption in SMEs: an integrated framework," Int. J. Entrep. Behav. Res., vol. 15, no. 2, pp. 162-186, Mar. 2009.

18. Y. K. Dwivedi et al., "Research on information systems failures and successes: Status update and future directions," Inf. Syst. Front., vol. 17, no. 1, pp. 143-157, Feb. 2015.

19. M. Levy and P. Powell, Strategies for Growth in SMEs. Elsevier, 2005.

20. S. Drew, "Strategic Uses of E-Commerce by SMEs in the East of England," Eur. Manag. J., vol. 21, no. 1, pp. 79-88, Feb. 2003.

21. S. Sarosa, "The information technology adoption process within Indonesian small and medium enterprises," 2007.

22. S. Rivard, L. Lapointe, and A. Kappos, "An Organizational Culture-Based Theory of Clinical Information Systems Implementation in Hospitals," J. Assoc. Inf. Syst., vol. 12, no. 2, pp. 123-162, Feb. 2011.

23. S. Newell, S. L. Pan, R. Galliers, and J. Huang, The Myth of the Boundaryless Organization, vol. 44. 2001.

24. K. Reinecke and A. Bernstein, Knowing what a user likes: A design science approach to interfaces that automatically adapt to culture, vol. 37. 2013.

25. J. Whatley, "Using information technology effectively in teaching and learning.," Comput. Educ., vol. 30, no. 3, pp. 280-281, 1998.

26. E. M. Rogers, Diffusion of innovations. Free Press, 2003.

27. C. Avgerou and T. Cornford, "Information systems and organizational change," in Developing Information Systems, London: Macmillan Education UK, 1998, pp. 229-256.

28. T. Teo, "Pre-Service Teachers' Attitudes towards Computer Use: A Singapore Survey.," Australas. J. Educ. Technol., vol. 24, no. 4, pp. 413-424, 2008.

29. P. McAndrew, "Handbook on Information Technologies for Education and Training," Comput. Educ., vol. 39, no. 2, pp. 201-203, Sep. 2002.

30. Rangaswamy and S. Gupta, Innovation adoption and diffusion in the digital environment: Some research opportunities, vol. 75-96. 2000.

31. Demirci, How do teachers approach new technologies: geography teachers' attitudes towards geographic information systems (GIS), vol. 1. 2009.

32. C.-H. Chen, "Why Do Teachers Not Practice What They Believe Regarding Technology Integration?," J. Educ. Res., vol. 102 , no. 1 , pp. $65-75$, Sep. 2008.

33. J. Tondeur, M. Valcke, and J. Van Braak, "A multidimensional approach to determinants of computer use in primary education: teacher and school characteristics,” J. Comput. Assist. Learn., vol. 24, no. 6, pp. 494-506, Oct. 2008.

34. P. Lim and C. S. Chai, "Teachers' pedagogical beliefs and their planning and conduct of computer-mediated classroom lessons," Br. J. Educ. Technol., vol. 39, no. 5, pp. 807-828, Sep. 2008.

35. J. M. Clausen, "Beginning Teachers' Technology Use: First-Year Teacher Development and the Institutional Context's Affect on New Teachers' Instructional Technology Use with Students.," J. Res. Technol. Educ., vol. 39, no. 3, pp. 245-261, 2007.

36. E. J. Rozell and W. L. Gardner III, "Computer-related success and failure: a longitudinal field study of the factors influencing computer-related performance,” Comput. Human Behav., vol. 15, no. 1, pp. 1-10, 1999.

37. Farid, "English teachers' attitudes toward computer-assisted language learning," Int. J. Lang. Stud., 2010.

38. S.-S. Liaw, H.-M. Huang, and G.-D. Chen, "Surveying instructor and learner attitudes toward e-learning," Comput. Educ., vol. 49, no. 4, pp. 1066-1080, Dec. 2007.

39. T. Plomp, R. Anderson, N. Law, A. Quale, and I. Association for the Evaluation of Educational Achievement, Crossnational information and communication technology polices and practices in education. 2018.

40. B. the Book, Business Research Methodology. Dryden Press, 2011. 